\title{
Getting What You Pay For: Analyzing the Net Neutrality Debate
}

\author{
Mark A. Jamison \\ Public Utility Research Center \\ Department of Economics \\ University of Florida \\ and \\ Janice A. Hauge \\ Department of Economics \\ University of North Texas
}

April 20, 2008

\begin{abstract}
We analyze the effects of networks offering and charging for premium transmission service, which is central to the net neutrality debate. We find that when a network provider optimally charges for and provides premium transmission for content providers, innovation is stimulated on the edges of the network and smaller content providers benefit more than do larger content providers. Furthermore, we show that the network provider increases its investment in network capacity when it offers premium transmission without degrading service for content providers that do not purchase the premium service. Also the number of network subscribers increases.
\end{abstract}




\section{Introduction}

Numerous situations arise where sellers of goods and services pay for the opportunity to provide their products to consumers and even pay premium prices for superior delivery or access. For example package delivery services such as Federal Express and the United States Postal Service offer shippers a variety of delivery speeds and insurance programs. Web content providers such as Yahoo can purchase webcaching services from companies such as Akamai to speed the delivery of their web content to customers. ${ }^{1}$ Providing superior access to customers also occurs on the World Wide Web where web site providers can pay Google for premium placement on its search engine web pages to improve customers’ access to their web sites.

Recently there has been concern over the desires of some Internet Service Providers (ISPs) to offer Internet content providers faster, premium delivery of content and services to end user customers and to charge the content providers for the superior transmission. This is part of the so-called net neutrality issue. Net neutrality is a broad topic covering a number of issues (Wu, 2004), the exact specification of which varies across authors and over time. But the provision of and charging for premium transmission speed of Internet packets consistently appears in the public debate (Hahn and Wallsten, 2006). Proponents of net neutrality, such as $\mathrm{Wu}(2003,2004)$ argue innovation should only occur at the edges of the network and that the network itself is simply infrastructure that should not add value. Net neutrality proponents also hold that the network should be a commons that broadband users are allowed to use in ways that are not illegal and that do not harm the network and that networks should not discriminate between uses, users,

\footnotetext{
${ }^{1}$ Akamai provides a service called dynamic site delivery that caches web content for faster delivery to Internet users. Akamai lists Yahoo as one of the customers of this service http://www.akamai.com/html/customers/customer_list.html, downloaded February 18, 2007.
} 
and content. (Wu, 2004) In contrast, network providers such as AT\&T argue that offering premium transmission services will improve customer choice and that ISPs would not degrade anyone’s service. (Whitacre, 2006)

In this paper we focus on the issue of whether networks should be allowed to offer and charge for premium transmission service. We find that when a network provider optimally charges for and provides premium transmission for content providers, innovation is stimulated on the edges of the network, contrary to the conclusions of Yoo (2004) and Wu (2003). Furthermore we show that a network provider will choose to increase its network capacity when it offers premium transmission without degrading service for content providers that do not purchase the premium service. This appears to conflict with Cheng et al. (2007), which concludes that a network provider has less incentive to invest in network capacity when offering premium transmission than when it does not offer the premium service.

Our model considers a situation in which a single network provides consumers with network access and supplies content providers with transmission of their content to consumers. $^{2}$ This network provider is not also a content provider. There are a large number of possible content providers who differ in their ability to produce valuable content. Their only source of revenue is advertising and each content provider chooses whether to produce and how much to invest in content. Consumers value content and the speed of delivery. We focus our analysis on content such as news sites and search engines whose content value does not degrade in value with a few moments delay, i.e., the value of the content and the value of speed are separable.

\footnotetext{
${ }^{2}$ We assume a monopoly network to simplify our analysis.
} 
When only a single transmission speed is offered by the network provider, some low-value content providers choose to not produce because their potential advertising revenue would not cover their content production costs and their fixed costs. However, when a premium transmission speed is offered, some low-value sites that did not produce under the single speed scenario find it profitable to purchase the premium speed and so choose to enter the market. This results in an increase in the amount and diversity of content available for consumers. We consider this increase in the variety of content on the network to constitute innovation on the edges, which raises the value of the network.

The rest of this paper is organized as follows. Section II provides background on the Internet and on the net neutrality debate. Section III describes our model. Section IV examines how content providers choose their content and transmission speeds. Section V addresses affects on retail Internet access markets. Section VI is the conclusion. All proofs are in the appendix.

\section{Background}

The net neutrality debate began being discussed in the public arena in 2003 with the Supreme Court reversal of the Ninth Circuit court ruling in Brand X Internet Services v. $F C C^{3}$ The Supreme Court's decision upheld the Federal Communications Commission's (FCC's) conclusion that cable modems are an information service, and, as such, are not subject to the regulations used in the telephone and cable television industries. Further, the Supreme Court stated that the FCC had the authority, under its Title I jurisdiction, to impose regulation on the Internet industry in the future, if

\footnotetext{
${ }^{3}$ Case filed October 6, 2003.
} 
necessary. ${ }^{4}$ This led to intense lobbying on the part of the telephone companies to have DSL modems treated similarly to cable modems. The FCC issued a ruling in $2005^{5}$ that exempted DSL from the "statutory access requirements applied to traditional telephone [service]”. ${ }^{6}$ This effectively left the provisioning of Internet service without a traditional telecommunications regulatory framework in which to work.

Currently, all traffic that transits the Internet is delivered on a best effort basis. In practice, this means that the first data into a switching point are the first data out of a switching point. The proponents of network neutrality legislation foresee this application blind version of the Internet as being in jeopardy. The network neutrality proponents' apprehension over the neutrality of the Internet stems from a perception on their part that the FCC and the federal courts are not exercising rigorous oversight of ISPs, ${ }^{7}$ particularly the ISP's owned and operated by traditional telephone companies. ${ }^{8}$ Recent quotes by telephone company executives suggest that the phone companies may charge ISPs for bandwidth given the chance. For example, Verizon CEO Ivan Seidenberg stated, "We have to make sure that they [application providers] don't sit on our network and chew up bandwidth... We need to pay for the pipe."9 Similarly, SBC’s CEO Edward Whitacre in 2005 was quoted as saying "How do you think [content providers] are going to get to customers? Through a broadband pipe. Cable companies have them. We have them. Now

\footnotetext{
${ }^{4}$ National Cable \& Telecommunications Assn. V. Brand X Internet Services (04-277) 345 F.3d 1120.

${ }^{5}$ See Appropriate Framework for Broadband Access to the Internet over Wireline Facilities, Report and Order and Notice of Proposed Rulemaking, 20 FCCR 14853.

${ }^{6}$ Yoo, Network Neutrality, pg. 1858.

${ }^{7}$ For a more detailed discussion of the lack of oversight from the federal courts and FCC see Prepared Statement of Earl W. Comstock for United States House of Representatives Committee on the Judiciary Telecommunications and Antitrust Task Force, submitted 25 April 2006.

${ }^{8}$ For more detail see testimony of Paul Misener, Earl W. Comstock and Timothy Wu before United States House of Representatives Committee on the Judiciary Telecommunications and Antitrust Task Force, 26 April 2006.

${ }^{9}$ Quoted on arstechnica.com website, January 6, 2006.
} 
what they would like to do is use my pipes [for] free, but I ain't (sic) going to let them do that because we have spent this capital and we have to have a return on it. So there's going to have to be some mechanism for these people who use these pipes to pay for the portion they're using. Why should they be allowed to use my pipes?”10 The FCC, for its part, believes that it is doing an adequate job of overseeing and promoting competition among ISP's, despite recent mergers in the telecoms industry. ${ }^{11}$ Whether the limited conditions imposed by the FCC are adequate is uncertain. Those in favor of network neutrality legislation do not think that they are; they fear that without legislative or regulatory safeguards the phone companies, and not the market, will decide which content providers are to be successful and which are not.

The current debate, then, is over what regulations if any are to be imposed on the Internet industry. Content providers (such as Google, Yahoo!, and Microsoft) are concerned about the stated desires of some ISPs to begin offering preferred delivery of data. For a fee, the ISPs would guarantee "head of the line” privileges for a customer's data. While there is some doubt as to the technical feasibility of such a plan if it were implemented, ${ }^{12}$ the implication is that whoever did not pay the extra fee would have the quality of service for their data degraded. ${ }^{13}$ At its most basic level, priority delivery of content is seen as a method by which ISPs could earn higher profits than they currently do through a form of price discrimination, while maintaining the ability to compel content providers to pay the additional fee or risk degradation of service. Furthermore

\footnotetext{
${ }^{10}$ As quoted in arstechnica.com in response to the question "How concerned are you about Internet upstarts like Google, MSN, Vonage and others?” October 31, 2005.

11 See High-Speed Services for Internet Access: Status as of June 30, 2006 available at www.fcc.gov/wcb/stats for data supporting the FCC assertion that the broadband market is competitive.

${ }^{12}$ See testimony of Gary R. Bachula, Vice President, Internet2 before the United States Senate Committee on Commerce, Science and Transportation. Testimony given 7 February 2006.

${ }^{13}$ See Paul Misener's testimony before the United States House of Representatives Committee on the Judiciary Telecommunications and Antitrust Task Force, 26 April 2006.
} 
those who are in favor of imposing network neutrality legislation believe that if the ISPs were able to use their market power over infrastructure as leverage to gain market power over content it would stifle application level innovation and consumers would suffer. The case of Madison River Communications ${ }^{14}$ is used by such proponents to illustrate how telecommunications companies would use their market power to embargo applications with which they do not want to compete.

On the other side of the debate are the ISPs (for example, AT\&T, Sprint/Nextel, and Comcast) whose basic argument for allowing premium delivery of data is that under the status quo they have no incentive to upgrade their networks, and limited ability to recoup costs of initial investments in the Internet.

Thus far, neither side in the debate has demonstrated willingness to compromise and their particular arguments for or against network neutrality often have been more rhetorical than rigorous. Because the focus of our paper is a formal analysis of the debate, we do not address some arguments frequently put forth by politicians, lobbyists, and the companies involved. Instead, we focus on the academic research to date, which has been rather limited. Research by Yoo and Wu focuses on the possibilities of light regulation that preserves the openness of the Internet without stifling competition and innovation. This view is contrasted by van Schewick, who argues that a network neutrality regime that favors content providers is the more socially beneficial arrangement. She posits that the benefits of application-level innovation outweigh the costs of little or no network

\footnotetext{
${ }^{14}$ Madison River Communications is a rural telecommunications company that blocked its DSL customers from accessing VoIP service. After it was brought to regulators attention, the FCC issued an order directing Madison River to allow its DSL customers to access VoIP service. See Madison River Communications Order FCC 4295 (2005).
} 
level innovation (van Schewick, 2005). In a related series of papers by Ford et $\mathrm{al}^{15}$ the authors analyze potential network neutrality legislation with respect to the welfare of the industry, consumer welfare, economic efficiency and rural broadband deployment. Generally they find that legislation that would limit market transactions would prove to be detrimental to all parties involved and may deter competition, reduce investment, and result in higher prices for consumers. Thus far, only van Schewick (2005), Laffont et al. (2003), and Hermalin and Katz (2007) have offered analytical frameworks for analyzing the Internet from an economic perspective. Laffont et al develop a model of Internet backbone competition, focusing on socially versus privately optimal access charges. While useful with respect to understanding competition among backbone owners, the model does not account for incentives to allow content providers' priority delivery as a profit-maximizing option. Additionally, it does not consider the possible effects of legislation on innovation. Hermalin and Katz (2007) develop a model similar to ours, but restrict themselves to the case in which content value degrades with delay and assume that transmission quality is exogenous if more than one quality is offered. While addressing important questions with respect to the debate, none of these works examine analytically two of the primary concerns with network neutrality legislation: the potential effect on network capacity and innovation. The current paper therefore adds to the literature by developing a general theoretical model designed to address the effects of net neutrality legislation on network capacity and innovation.

\footnotetext{
${ }^{15}$ See Phoenix Center Policy Papers Numbers 16, 24, 25 and 28 by Ford, Koutsky, and Spiwak.
} 


\section{The Model}

We consider a model where a network provider chooses transmission speeds and retail prices in the first stage of the game. Then the content providers decide whether to produce and each one that produces decides whether to use the standard transmission speed or the premium speed. Lastly, consumers choose whether to subscribe to the network service and use the content sites.

\section{a. Consumers}

Consumers value subscribing to network access and value content sites based on both the usefulness of the information provided and the speed with which the information is delivered. Let $v(I, S, \imath)^{16}$ represent the utility that a consumer receives from accessing the site of content provider $\imath=[0, \bar{l}]$, where higher values of $I$ represent more content and $\imath$ represents the content provider's innate ability to make information valuable. We might think of this as a situation where a consumer prefers a sports information site with more information to one that has less information, all other things being equal, but is willing to accept less information if the information provided is more accessible. $S \in\{\underline{S}, \bar{S}\}^{17}$ is the information delivery speed that a consumer experiences when she accesses $\imath$ 's content. Consumers prefer higher information value and faster delivery times to lower information value and slower delivery times, all other things being equal, i.e., $v_{I}>0, v_{S}>0, v_{t}>0$, and $v_{I, l}>0$ for all values of $I, S$, and $\iota$. $I$ and $S$ are strictly positive. This might represent a situation where the consumer values the information on a news site, but also values her time so that she prefers a site with less content value if the amount of time she needs to

\footnotetext{
${ }^{16}$ Hereafter we suppress the expressions in the parentheses wherever possible to conserve on notation.

17 We restrict the network provider to offering no more than two transmission speeds, premium and standard. However, at times it will be convenient for exposition to express $S$ as a continuous variable.
} 
wait on the content is sufficiently less than the time she has to wait on better content. Some news sites with lower innate abilities might find it less costly to increase consumer value by purchasing premium transmission from the network provider than by enhancing its content. As we will see below, this opportunity to substitute less costly premium transmission for more costly content enhancement results in innovation at the edges of the network.

Consumers value two types of content sites differently with respect to how speed affects the value of a site's content. In one situation speed increases the value of content, i.e., $v_{I, S}>0$. This is the situation examined by Hermalin and Katz (2007), so we do not repeat their analysis in our paper. ${ }^{18}$ Instead we consider the situation where content value may not be affected speed. This is the utility function developed by Mendelson (1985) and used by Bandyopadhyay and Cheng (2006) and Cheng et al. (2007); the consumer’s value of time is independent of the value derived from content, i.e., $v_{I, S}=0$ and $v_{t, S}=0$. This might represent situations such as news sites or search engines where modest delays do not affect the value of the content.

A consumer needs to purchase the network service before accessing content. Following Katz and Shapiro (1985), we assume that consumers are continuously and uniformly distributed with density one on a line from zero to one, where a consumer's location $\tau \in[0,1]$ represents the innate value that she places on accessing the network. A consumer of type $\tau$ that accesses the network and uses content receives a net consumer surplus of $\tau+\int_{\hat{\imath}}^{\bar{\imath}} v(z) d z-p$, where $p$ is the price the consumer pays the network provider

\footnotetext{
${ }^{18}$ In their formulation, content sites with greater innate abilities may value premium speed more than do content sites with lower innate abilities.
} 
and $\hat{\imath}$ is the marginal content provider, i.e., the content provider who is indifferent between producing and not producing. (We discuss this more below.) To simplify our analysis, we assume that every consumer of $\imath$ 's site experiences the same information value and delivery speed, and every consumer of the network service pays the same price. Standard analysis (e.g., Katz and Shapiro, 1985) shows that the number of consumers who purchase in equilibrium is $n \equiv 1-p+\int_{\hat{\imath}}^{\bar{\imath}} v(z) d z$ and that the market clearing price is $p=1-n+\int_{\hat{\imath}}^{\bar{\imath}} v(z) d z$

\section{b. Content Providers}

Each content provider seeks to maximize individual profits and content providers are distributed uniformly on a line from 0 to $\bar{l}$, where $\bar{l}$ is an arbitrarily large number. $w$ represents the constant marginal cost of producing content, and $r(S) \geq 0$ represents the price the network provider charges a content provider for connection to the network such that $r(\underline{S})$ is the price paid by each content provider that chooses standard transmission speed and $r(\bar{S})$ is the price paid by each content provider that chooses premium speed. We consider a tariff structure in which the content provider pays the network provider based on the content provider's expected capacity needs. We simplify this tariff structure so that the content provider pays a constant price $r(S)$ times the capacity needed, which we simplify to the number of expected hits on the content site.

We assume content providers do not charge consumers who access their sites, but instead receive revenue from advertisers who value access to consumers who access content. This is a standard practice in the Internet. 
There is a competitive market for advertising on content sites so that each advertiser takes the number of hits on a content site as given. The market demand for advertising is given by $a \equiv a(h)$, where $a$ is the price paid by the advertiser to a content provider when a consumer views the site and $h$ represents the number of hits on all content sites on the network. The price the advertiser is willing to pay per hit is decreasing in the number of hits. To ensure that at least one content provider chooses to produce in equilibrium, we assume that $a(1)>0$.

The number of hits received by a content provider is increasing in the number of consumers connected to the network and in the value provided by the site. Normalizing the relationship between utility and hits so that they can be expressed in the same units, we express the expected number of hits on $\imath$ 's site as $h_{t}=v \cdot n$. This would mean, for example, that the number of hits expected on Google's web site increases with the number of Internet users and with the value of Google's site. The total number of hits for all sites is defined as $h \equiv \int_{\hat{\imath}}^{\bar{\imath}} h_{z} d z$. The total advertising dollars paid to all content providers is $a \cdot h$ and content provider $\iota$ expects revenue of $a \cdot h_{l}$.

Because the content market is competitive, each content provider takes $a, r(S)$, and $n$ as given when choosing $I$ and $S$. We can now express content provider $\iota$ 's profit maximization problem as 


$$
\begin{aligned}
& \max _{I, S} \pi_{l} \equiv h_{l}(a \cdot-r(S))-w \cdot I \\
& \text { Subject to } \quad I>0 \\
& \qquad S \in\{\underline{S}, \bar{S}\} .
\end{aligned}
$$

The marginal content provider $\hat{\imath}$ is the one for whom $h\left(I^{*}, S^{*}, \hat{\imath}\right)\left(a-r\left(S^{*}\right)\right)-w \cdot I^{*}=0$.

This optimization leads to Lemma 1.

Lemma 1. Content providers' preferences for premium service are unaffected by the number of consumers connected to the network.

This finding results from each content provider's belief that its choice does not influence the number of consumers using the network and from the design of the network provider's tariff for content providers. In our model content providers' advertising revenue and costs for speed are both linear with respect to the number of hits a content site expects. This finding is the same as the finding of Hermalin and Katz (2007) in their examination of e-Bay like sites.

\section{c. Network Provider}

There is a single, profit maximizing network provider who supplies consumers with network access and supplies content providers with transmission of their content to consumers. The network provider does not provide content. We describe above the network provider's prices to consumers and to content providers. Let $C(\mu)$ represent the network provider's production costs for providing network capacity $\mu, C^{\prime}>0$ and $C^{\prime \prime}>0$, the constant marginal cost of providing network access to a consumer is $c$, and we 
normalize the network provider's fixed costs to zero. We describe next how the network provider supplies transmission speed and network capacity.

\section{d. Premium Service ${ }^{19}$}

To simplify our analysis, we assume each consumer visit to a site triggers transmission of a uniform amount of content through the network. Following Mendelson (1985), we adopt the common assumption that the times between consecutive requests for information by consumers are independent identically distributed random variables with finite mean $1 / h$ where $h$ is the arrival rate of requests for content into the network, which we call hits. Normalizing the measure of content demanded per unit of time to $1, h$ represents the total number of consumer requests for information from content sites. ${ }^{20}$ We assume a queuing system for hits with a Poisson arrival process, which is standard for analysis of computing systems where the number of users in the network is large, the impact of a single user on network performance is small, and all users are independent. ${ }^{21}$ Applying Little's Law, which states that the average number of jobs in a stable system is equal to their arrival rate times their average time in the system, the average wait time for consumers in the network is $W=\frac{1}{\mu-h}$ when no premium service is provided, where $\mu$ is the capacity of the network, or its ability to deliver the desired arrival rate (Gross and Harris, 1998, pp. 10-13). We represent the average speed for the network as the inverse of the average wait time for consumers. ${ }^{22}$

\footnotetext{
${ }^{19}$ We would like to thank Hsing Kenneth Cheng and Subhajyoti Bandyopadhyay for identifying relevant literature on queuing theory.

${ }^{20}$ Note that since $h$ is a function of $v$ and $n, h$ varies with both.

${ }^{21}$ This is approximated by an $M / M / 1$ queuing system, which is a queuing system where interval and distribution times are exponentially distributed and there is one server.

${ }^{22}$ Note that as the number of users approaches the network's capacity, the average wait time approaches infinity and speed approaches zero.
} 
Providing faster transmission for some content - which is what we call premium service - may affect the average wait time in a network depending on how the premium service is provided (Gross and Harris, 1998, p. 150). As we indicate above, some network providers have committed to not degrading service for any customer if premium service is offered. We call this the non-degradation condition.

Non-Degradation Condition. Under this condition, the network operator keeps its commitment that standard transmission service will be the same regardless of whether premium service is offered.

It is beyond the scope of this paper to examine how network providers technically might provide premium service, but the following lemma holds for all methods applicable to the network model described above.

Lemma 2. When the non-degradation condition holds, a network provider will increase network capacity when providing premium transmission service.

Lemma 2 results from a direct application of queuing theory. (See Gross and Harris, 1998, pp. 141-151) There are two basic methods of improving the speed of delivery for one group's content over another group's content when capacity is limited so that there is a queue. One method is to allow the first group to always get ahead in line. When this approach is used, the second group would experience a decrease in its service speed because it loses its place in line unless the total system speeds up. Thus network capacity has to be increased if the first group experiences an improvement in service while the second group experiences no degradation in its service. The other method for 
improving one group's speed is to increase the delivery rate that is at its command. With this approach, the second group would experience an increase in wait time unless total network capacity was increased so that the second group's access to delivery capacity was not diminished. Thus when the non-degradation condition holds, the network's provision of premium transmission results in an increase in network capacity, all other things remaining equal.

e. Other Assumptions

To ensure that in equilibrium at least some consumers buy network access and some content providers choose to produce, we assume that for some transmission speed greater than the standard speed, that marginal revenue for at least some content providers is positive. We further assume that the marginal cost of network capacity is sufficiently low relative to consumers' willingness to pay that the network operator is willing to supply network capacity.

We can now express the network provider's objective function as:

$$
\begin{gathered}
\max _{p, \hat{\imath}, S} \pi \equiv(p-c) n+\int_{\hat{\imath}}^{\bar{\imath}} r(S) v(z) \cdot d z-C(\mu) \\
\text { Subject to } \quad r \geq 0 \\
S \in\{\underline{S}, \bar{S}\}
\end{gathered}
$$

Transmission speed and output both affect the need for network capacity, namely, $\mu_{S}>0, \mu_{S, S}>0, \mu_{t}>0, \mu_{t, t}>0$, and $\mu_{S, t}>0$ 


\section{Innovation at the Edges}

Net neutrality advocates hold that allowing network providers to supply and charge for premium transmission would hinder innovation at the edges of the network, including content sites. Interpreting innovation to mean the value and diversity ${ }^{23}$ of content available at the edges of the network, we find the opposite to be true. This is explained with Proposition 1.

Proposition 1. The diversity of content at the edges of the network increases when the network provider optimally chooses to offer premium transmission services. Furthermore, the value that consumers receive from the sites that purchase the premium transmission service is greater than the value they would receive if the premium service were not offered.

To understand the logic of Proposition 1, consider first that a profit maximizing network provider will introduce premium transmission only if at least one content provider will purchase the premium service. Now consider what type of content provider is more likely to purchase the premium service, a provider with innately lower value content (a lower value of $\imath$ ) or one with innately higher value content (a higher value of $\imath$ ). Because the network provider charges for speed based on the volume of traffic for a content site, the marginal cost of speed is greater for a higher value site than for a lower value site, so the higher value site has a lower preference for premium transmission.

\footnotetext{
${ }^{23}$ We define diversity as the number of content sites. Thus we consider an increase in the number of content sites as an increase in diversity.
} 
Now consider how the offering of premium transmission service affects the potential content provider that is just to the left of the marginal provider on the continuum from 0 to $\bar{l}$, i.e., just to the left of $\hat{\imath}$. This potential provider will purchase the premium service before any of the existing content providers and, once it purchases the premium service, is able to at least break even. As a result the number of content sites on the network increases because of the provision of the premium transmission service.

One result from Proposition 1 is that consumers receive greater utility from content sites that purchase the premium speed than they would have were the premium service not available. This happens because content providers will purchase the premium speed only if it increases revenues, which happens only if the premium speed increases hits on these sites by increasing the utility that consumers receive from the sites that purchase the premium service.

It also follows from Proposition 1 that when lower value content sites purchase the premium speed and the non-degradation condition applies, profits decrease for the sites that do not purchase it. This results from the downward sloping demand curve for advertising on content sites. When the overall amount of content increases, the total number of hits increases, which causes the price paid for advertising on content sites to decrease. This leads to a decrease in revenue, and thus profits, for every content site that does not increase its hits by purchasing the premium transmission service. This leads to Corollary 1A.

Corollary 1A. When premium transmission service is offered and at least one content site purchases the service, profits for content sites that do not purchase the premium 
service are lower than if the premium service had not been offered, all other things being equal.

As we explain above, Corollary 1A results from the combination of an increase in the number of content sites made available to consumers, the increased number of hits on sites that do purchase the premium transmission service, and the declining marginal utility of content. Furthermore, Corollary $1 \mathrm{~A}$ may help us understand why content providers with very large web presence are some of the strongest proponents of net neutrality: They stand to lose market share and advertising revenue to smaller web sites that are the more likely purchasers of premium services. However, they may have other reasons as well. What is less clear is why there are claims that small web content providers are also sometimes opposed to networks offering premium service. Perhaps this opposition is a small, select group of smaller content providers in special circumstances, such as those whose content degrades with time, or perhaps the smaller providers who are used as examples have not adequately analyzed the effects that premium service might have on their businesses.

Corollary $1 \mathrm{~A}$ does not mean that all content providers purchase the premium service. From revealed preferences we know that a network provider that had optimally chosen a standard speed when offering only one speed, and that had optimally chosen a premium speed when choosing to provide more than one speed, would choose a premium speed that not all content providers would purchase. 


\section{Network Subscription}

We now turn our attention to the effects of premium transmission service on demand for network subscription. Proposition 2 provides this section’s main result.

Proposition 2. When the non-degradation situation holds, more consumers subscribe to the network service when premium transmission service is offered and at least one content site purchases the service than if the network provider did not offer the premium service.

More consumers choose to subscribe to the network service because the value of the network is greater when premium service is provided than when it is not. The network provider benefits in two ways from providing the premium transmission service. First, it receives higher profits by being able to charge premium prices for something that at least some content providers value, whereas without the premium prices there would be no direct benefit to offering a higher speed service. Second, the number of consumers subscribing to network access is greater, which in turn leads to more hits on the content sites, which stimulates the demand for premium transmission by the lower-value content sites. The greater diversity of content sites also stimulates demand by consumers for network access and increases the number of content sites interested in purchasing the premium transmission service. 


\section{Conclusion}

In this paper we analyze the effects of a network provider offering premium transmission speeds for content providers. We find that the claims of the net neutrality advocates do not hold when network providers keep their commitment to not degrade service. Specifically, we find that offering premium service stimulates innovation on the edges of the network because lower-value content sites are better able to compete with higher-value sites with the availability of the premium service. The greater diversity of content and the greater value created by sites that purchase the premium service benefit advertisers because consumers visit content sites more frequently. Consumers also benefit from lower network access prices. We also find that that network capacity expands with the offering of the premium service.

We omit three important issues from our analysis that should be considered in future work. One issue is how the offering of premium transmission might affect the network provider's incentive to change the standard transmission speed. At least AT\&T has committed to not degrade service for any network user, but it is unclear how such a commitment would be enforced. Secondly, we do not analyze the effects of peer-to-peer communication. Peer-to-peer communication, which is communication between consumers rather than between consumers and content sites, is growing in importance on the Internet. Thirdly, we do not consider the effects of the network provider vertically integrating and providing content. There is some concern that this would provide an incentive for foreclosure by the network provider. However, this might not be the case if the network provider can engage in price discrimination when charging for premium transmission. 


\section{References}

Bandyopadhyay, S. and H. K. Cheng (2006). "Liquid Pricing For Digital Infrastructure Services." International Journal of Electronic Commerce 10(4): 47-72.

Cheng, Hsing Kenneth, Subhajyoti Bandyopadhyay and Hong Guo. 2007. "The Debate on Net Neutrality: A Policy Perspective,” Department of Decision and Information Sciences, University of Florida.

Federal Communications Commission. 2007. "High Speed Services for Internet Access: Status as of June 2006.”

Ford, George S., Thomas M. Koutsky, and Lawrence J. Spiwak. 2006. "The Efficiency Risk of Network Neutrality Rules.” Phoenix Center Policy Bulletin Number 16. Phoenix Center for Advanced Legal \& Economic Public Policy Studies.

Ford, George S., Thomas M. Koutsky, and Lawrence J. Spiwak. 2007. “Network Neutrality and Foreclosing Market Exchange: A Transaction Cost Analysis” Phoenix Center Policy Bulletin Number 28. Phoenix Center for Advanced Legal \& Economic Public Policy Studies.

Ford, George S., Thomas M. Koutsky, and Lawrence J. Spiwak. 2006. "Network Neutrality and Industry Structure.” Phoenix Center Policy Bulletin Number 24. Phoenix Center for Advanced Legal \& Economic Public Policy Studies.

Ford, George S., Thomas M. Koutsky, and Lawrence J. Spiwak. 2006. “The Burden of Network Neutrality Mandates on Rural Broadband Deployment.” Phoenix Center Policy Bulletin Number 25. Phoenix Center for Advanced Legal \& Economic Public Policy Studies.

Gross, Donald and Carl M. Harris. 1998. Fundamentals of Queueing Theory. $3^{\text {rd }}$ Edition. New York, NY: John Wiley \& Sons.

Hahn, Robert and Scott Wallsten. 2006. "The Economics of Net Neutrality." The Economists' Voice Vol. 3, Issue 6, pp. 1-7.

Laffont, Jean-Jaccques, Scott Marcus, Patrick Rey, and Jean Tirole. 2003. "Internet Interconnection and the Off-Net-Cost Pricing Principle." The RAND Journal of Economics, Vol. 34, No. 2, pp. 370-390.

Mendelson, Haim. 1985. "Pricing Computer Services: Queueing Effects." Communications of the ACM Vol. 28, No. 3, pp. 312-321. 
van Schewick, Barbara. 2007. "Towards an Economic Framework for Network Neutrality Regulation,” Journal on Telecommunications and High Technology Law, Vol. 5, No. 2, pp. 329-392.

Whitacre, Ed. 2006. Keynote Session at TelecomNEXT, Mandalay Bay and Convention Center Las Vegas, NV.

Wu, Tim. 2003. "Network Neutrality, Broadband Discrimination,” Journal of Telecommunications and High Technology Law, Vol. 3, No. 1. pp. 141-176.

Wu, Tim. 2004. "The Broadband Debate, a User's Guide," Journal on Telecommunications and High Technology Law, Vol. 3, No. 1, pp. 69-96.

Yoo, Christopher S. 2004. "Would Mandating Broadband Network Neutrality Help or Hurt Competition? A Comment on the End-to-End Debate," Journal on Telecommunications and High Technology Law, Vol. 3, No. 1, pp. 23-68.

Yoo, Christopher S. 2006. "Network Neutrality and the Economics of Congestion," The Georgetown Law Journal, 94, pg 1847-1858. 


\section{Appendix}

\section{Proof of Lemma 1.}

See the proof of Proposition 2.

\section{Proof of Lemma 2.}

It is trivial to show that the network provider will optimally choose to offer premium transmission only if at least one content site provider purchases the premium service, so we will take that as given and consider how the network provider's choice to offer premium delivery affects the number of web sites offered and the quality of web sites. In Proposition 2 we show that offering premium transmission lowers $\hat{\imath}$, i.e., it increases the number of content providers. Furthermore, premium transmission increases the number of hits. So it is adequate for the immediate proof to show that the network provider increases network capacity even if the number of content sites and number of hits does not increase.

Consider a network model of the type $M / M / 1$ where there are two groups of content providers, 1 and 2, and that content from group 1 is given priority over the content of group 2 in terms of queuing, but not in terms of service. Queuing refers to the line that forms of requests for transmission that have not yet been served. Service refers to delivering the content to the network subscriber. The priority models we consider allow group 1's content to move ahead of group 2's content in the queue, but does not stop group 2's content from being delivered once group 2's content is in the service process. First consider a priority model in which there is only one service rate, which corresponds to our network capacity $\mu$. Gross and Harris (1998, pp. 146-147) shows that in this one service rate situation the wait time for group 1 is $W_{1}=\frac{h / \mu}{\mu-h_{1}}$, where $h$ is the sum of the requests for transmission of the two groups, i.e. $h=h_{1}+h_{2}$. Representing the speed of transmission for group 1 as the inverse of speed, i.e., $S_{1}=\frac{1}{W_{1}}$, then the partial derivative of speed with respect to capacity is $\frac{\partial S_{1}}{\partial \mu}=\frac{2 \mu-h_{1}}{h}>0$. So increasing the speed of group 1 while keeping the speed for group 2 constant in the one service rate situation requires an increase in network capacity.

Now consider a two rate situation, such that $\mu_{1}$ represents the rate at which group 1 is served and $\mu_{2}$ represents the rate at which group 2 is served. There are two possibilities for this situation: One approach would give group 1 priority in queuing and the other would not. Gross and Harris (1998, pp. 150) shows that regardless of which 
approach is used, $\frac{1}{\mu}=\frac{h_{1} / h}{\mu_{1}}+\frac{h_{2} / h}{\mu_{2}}$. The derivative of network capacity to group 1's rate is $\frac{\partial \mu}{\partial \mu_{1}}=\frac{\mu^{2} h_{1}}{\mu_{1} h}>0$, so increasing the speed for group 1 while leaving the speed for group 2 constant in the two service rate situation requires an increase in network capacity. QED

\section{Proof of Proposition 1.}

For ease of exposition in this proof, we treat $S$ as a continuous variable. From (1), first order conditions for an internal solution include

$$
v_{I} \cdot n(a-r)-w=0
$$

and

$$
v_{S} \cdot n(a-r)-r_{S} v \cdot n=0 .
$$

Notice that in (A2), $n$ does not affect the choice of S. This confirms Lemma 1.

Taking the total derivates of (A1) and (A2) with respect to $I, S$, and $\imath$ and applying Cramer's rule gives us

and

$$
\left[\begin{array}{cc}
v_{I, I} \cdot n(a-r) & -r_{S} v_{I} n \\
-r_{S} v_{I} n & n\left(v_{S, S}(a-r)-2 r_{S} v_{S}-r_{S, S} v\right)
\end{array}\right] \cdot\left[\begin{array}{l}
d I \\
d S
\end{array}\right]=\left[\begin{array}{c}
-v_{I, l} \cdot n(a-r) \\
n r_{S} v_{\iota}
\end{array}\right] \cdot d \imath
$$

$$
\frac{d S}{d l}=\frac{\left(v_{I, I} \cdot n(a-r)\right)\left(n r_{S} v_{l}\right)-\left(-r_{S} v_{I} n\right)\left(-v_{I, l} \cdot n(a-r)\right)}{\left(v_{I, I} \cdot n(a-r)\right)\left(n\left(v_{S, S}(a-r)-2 r_{S} v_{S}-r_{S, S} v\right)\right)-\left(-r_{S} v_{I} n\right)^{2}} .
$$

The denominator in (A3) is positive because of the assumption that second order conditions are met. Furthermore, the numerator is negative because $v_{I, I} \cdot n(a-r)<0$ because $v_{I, I}<0$ by assumption and $a-r>0$ from (A1), $n r_{S} v_{l}>0,-r_{S} v_{I}<0$, and $-v_{I, l} \cdot n(a-r)<0$ because $-v_{I, l}<0$ by assumption and $a-r>0$. Therefore $\frac{d S}{d \imath}<0$, which means that content providers with lower values of $\delta$ prefer higher speeds than do content providers with higher values of $\imath$, all other things being equal. QED.

\section{Proof of Corollary 1A.}

$$
\begin{aligned}
& \text { Because } \frac{\partial a}{\partial h}<0,\left.a\right|_{S=\underline{S}}>\left.a\right|_{S=[\underline{S}, \bar{S}]} \text {. Furthermore, from the proof of Proposition 2, }
\end{aligned}
$$

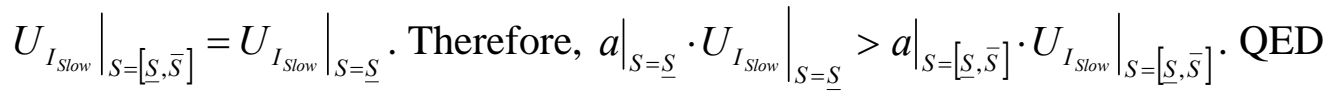




\section{Proof of Proposition 2.}

From (2), the network provider's first order conditions for choosing the consumer price when premium service is offered and provided includes

$$
\pi_{p}=-(p-c)+1-p+\int_{\hat{\imath}}^{\bar{\imath}} v(z) d z-\int_{\hat{\imath}}^{\bar{\imath}} r v(z) d z=0
$$

when the network provider offers only one transmission speed and

$$
\pi_{p}=-(p-c)+1-p+\int_{\hat{\imath}}^{\bar{\imath}} v(z) d z-\int_{\hat{\imath}}^{\bar{\imath}} r v(z) d z+\int_{\hat{\imath}}^{\hat{\imath}} \Delta v(z) d z-\int_{\hat{\imath}}^{\hat{\imath}} \Delta r \cdot \Delta v(z) d z=0
$$

where the network provider offers two transmission speeds, where $\Delta r=\bar{r}-\underline{r}$ and $\Delta v=\bar{v}-\underline{v}$. Solving for $p$ in both (A4) and (A5) and substituting into their respective expressions for the number of subscribers to the network, we have

$$
\Delta n=\int_{\hat{\imath}}^{\hat{\imath}} \Delta r d z>0
$$

where $\Delta n$ is the difference between the number of network subscribers when two speeds are provided and the number when only one is provided. QED 